\title{
HUBUNGAN JUMLAH OBAT YANG DIGUNAKAN TERHADAP RISIKO TERJADINYA DRUG-RELATED PROBLEMS PADA PASIEN ASMA DI SUATU RUMAH SAKIT DI SURABAYA
}

\author{
Amelia Lorensia ${ }^{1}$, Rizka I Wijaya ${ }^{2}$ \\ ${ }^{1}$ Departemen Farmasi Klinis-Komunitas, Fakultas Farmasi, Universitas Surabaya \\ ${ }^{2}$ Mahasiswa Apoteker, Fakultas Farmasi, Universitas Surabaya \\ Email: amelia.lorensia@gmail.com
}

\begin{abstract}
ABSTRAK
Asma adalah gangguan inflamasi kronis pada saluran pernapasan beresiko polifarmasi, yang berhubungan dengan peningkatan risiko masalah terkait obat (DRPs) dan hasil klinis yang merugikan. Penelitian ini bertujuan untuk menganalisis hubungan antara jumlah obat yang digunakan dengan kejadian DRPs pada pasien asma di rumah sakit. Penelitian menggunakan metode retrospektif, dengan menganalisis catatan medis dari pasien yang menjalani rawat inap asma selama 2 tahun. Jumlah pasien dianalisis adalah 60 orang. Hasil penelitian yang dilakukan dengan uji Spearman untuk uji non-parametrik, menunjukkan bahwa ada korelasi antara jumlah obat dengan jenis obat DRPs yang kurang tepat ( $\mathrm{p}$ $<0,05$ ), sehingga semakin banyak jenis obat yang digunakan oleh pasien dengan asma, semakin besar risiko pasien mendapatkan obat yang kurang tepat. Oleh karena itu dibutuhkan peran apoteker dalam pemantauan dan merekomendasikan obat rasional untuk pasien asma yang menjalani rawat inap di rumah sakit, untuk pengobatan diperoleh dengan pasien yang efektif dan optimal.
\end{abstract}

Kata kunci: asma, risiko masalah terkait obat

\begin{abstract}
Asthma is a chronic inflammatory disorder of the respiratory tract are at risk of polypharmacy, which is associated with an increased risk of drug-related problems (DRPs) and adverse clinical outcomes. This study aimed to analyze the relationship between the amount of drug used with the incidence of DRPs in hospitalized asthma patients. Research were using retrospective methods, by analyzing the medical records of patients undergoing asthma hospitalizations for 2 years. The number of patients analyzed was 60 people. Results of research conducted by the Spearman test for non-parametric tests, show that there is a correlation between the amount of drug to the type of drugs that are less precise DRPs ( $\mathrm{p}<0.05$ ), so that more and more types of drugs used by patients with asthma, the greater the risk of patients getting the drug less appropriate. Therefore it takes the role of pharmacists in monitoring and recommending rational drug for asthma patients who underwent inpatient in a hospital, for treatment obtained by the patient effective and optimal.
\end{abstract}

Key word: asthma, drug-related problem risk 


\section{PENDAHULUAN}

The National Asthma Education and Prevention Program (NAEPP) mendifinisikan asma sebagai gangguan inflamasi kronik pada saluran pernafasan yang menyebabkan episode berulang dari wheezing, sesak, chest thightness, dan batuk. ${ }^{1-3}$ Tujuan terapi asma yaitu: meringankan atau menghilangkan gejala kronik, meringankan atau menghilangkan eksaserbasi, aktivitas yang tidak terbatas, memelihara fungsi paru normal, meminimalkan penggunaan beta- 2 agonis aksi cepat, dan meminimalkan atau menghilangkan efek yang tidak dikehendaki dari obat. ${ }^{1,2,4,5}$ Setiap pasien harus dinilai untuk menemukan terapi regimen yang tepat, kepatuhan terhadap pengobatan, dan tingkat kontrol asma. Ketika kontrol asma telah tercapai, monitoring berkelanjutan adalah penting untuk memelihara kontrol dan untuk menemukan langkah terendah dan dosis terkecil dari terapi, dengan meminimalkan harga dan memaksimalkan keamanan terapi. ${ }^{1}$ Oleh karena terapi pada asma yang bersifat heterogen, tergantung dari kondisi klinis, fungsi, dan outcomes klinisnya. Sehingga pada pasien asma berisiko mengalami polifarmasi. ${ }^{6,7}$

Polifarmasi berkaitan dengan peningkatan risiko terjadinya drugrelated problems (DRPs), dan outcomes klinik yang merugikan. ${ }^{7,8}$ Pada penelitian yang dilakukan oleh Kirsten et al. (2007) di lima rumah sakit di Norwegia, menunjukkan bahwa jumlah risiko potensial terjadinya DRPs tiap pasien berhubungan linier terhadap jumlah obat yang digunakan saat pasien dirawat di rumah sakit, namun menjadi terbatas ketika menilai DRPs pada kondisi klinis secara aktual. ${ }^{10,11}$ Drug-Related Problem merupakan suatu kejadian atau keadaan yang tidak diinginkan yang dialami oleh pasien yang terlibat atau dicurigai yang melibatkan terapi pengobatan yang bersifat aktual dan potensial yang mempengaruhi outcome kesehatan. ${ }^{12,13} \mathrm{Di}$ antara faktor potensi DRPs, hubungan antara polifarmasi dan kejadian ADR (adverse drug reaction) telah paling banyak dipelajari dan didokumentasikan. Insiden ADR secara konsisten terbukti meningkatkan dalam eksponensial daripada secara linear dengan jumlah obat yang dikonsumsi. ${ }^{8}$

DRPs dapat menyebabkan outcomes yang tidak diinginkan yang meningkatkan morbiditas dan mortalitas. Bootman (2007) menyatakan bahwapharmaceutical care dapat menjadi strategi yang tepat untuk mencegah dan mengontrol morbiditas dan mortalitas yang disebabkan DRPs, sehingga dapat memperbaiki outcomes farmakoterapi dan kualitas hidup pasien. Oleh karena itu, farmasis perlu melaksanakan perannya dalam pharmaceutical care untuk menilai adanya drug-related problems (DRPs) dalam pengobatan pasien, ${ }^{14}$ dengan mengidentifikasi dan mengkoreksi penyebab potensial yang menyebabkan masalah dalam farmakoterapi. ${ }^{10,13,15}$ Oleh karena itu, penelitian ini bertujuan untuk menganalisa hubungan antara jumlah obat yang digunakan dan kejadian DRPs pada pasien asma rawat inap di rumah sakit.

\section{BAHAN DAN METODE}

Ruang lingkup ilmu dalam penelitian ini adalah Bagian Bangsal Penyakit Dalam RS Adi Husada Undaan Wetan Surabaya. Waktu penelitian ini adalah bulan November 2008 sampai dengan November 2010. Tempat pengambilan data dilakukan di Bagian Catatan Medik RS RS Adi Husada Undaan Wetan Surabaya. Penelitian ini merupakan studi observasional. Rancangan penelitian menggunakan desain retrospektif, yaitu dengan cara menggambil data dari rekam medis pasien asma rawat inap di Rumah Sakit Adi Husada Undaan Wetan selama 2 tahun, dimulai dari bulan November 2008 sampai dengan November 2010. Variabel 
bebas dalam penelitian ini adalah obat yang digunakan pasien asma (terdiri dari rata-rata jumlah obat per hari, jenis obat, dosis, durasi, rute pemberian), keluhan pasien, serta hasil laboratorium pasien selama dirawat. Sedangkan variabel tergantungnya adalah drug-related problems (DRPs).

DRPs didefinisikan sebagai

kejadian atau keadaan yang tidak diinginkan yang dialami oleh pasien yang terlibat atau dicurigai yang melibatkan terapi pengobatan yang bersifat aktual dan potensial yang mempengaruhi outcome kesehatan. ${ }^{12,13}$ DRPs

secara aktual adalah bila problem dipastikan ada, sedangkan DRPs secara potensial adalah bila diperlukan pengamatan lebih lanjut untuk memastikan apakan problem benar ada. ${ }^{15}$ Macam-macam DRPs terdiri dari: obat yang diperlukan (drug need), obat yang salah/tidak tepat (wrong/inappropriate drug), dosis yang salah (wrong dose), adverse drug reactions (ADRs), dan interaksi obat (drug interaction). ${ }^{12,15,16}$

Jumlah obat yang digunakan adalah jumlah golongan obat yang digunakan selama di rumah sakit, dengan dirata-rata dari penggunaan obat setiap harinya. Pasien diikatakan mengalami polifarmasi bila penggunaan $\geq 5$ obat saat masuk rumah sakit. ${ }^{17,18}$ Populasi penelitian ini adalah pasien asma yang pernah menjalani rawat inap di rumah sakit selama bulan November 2008 sampai dengan November 2010. Sampel penelitian ini adalah pasien asma yang pernah menjalani pengobatan rawat inap di rumah sakit selama bulan November 2008 sampai dengan November 2010. Kriteria inklusi pada penelitian ini adalah pasien asma yang tidak memiliki penyakit fungsi paru selain asma (penyakit paru obstruksi kronis, emfisema, bronkitis kronis, tuberkulosis, kanker paru, dll) serta pasien berusia dewasa $\geq 18$ tahun. Metode pengumpulan sampel penelitian yang digunakan dalam penelitian ini adalah yaitu purposive sampling sesuai dengan kriteria inklusi.

Data diambil dengan mengumpulkan catatan medik pasien mieloma multipel di RS Adi Husada Undaan Wetan Surabaya, kemudian dilakukan pencatatan data. Data yang dikumpulkan merupakan data sekunder dari catatan medik pasien asma rawat inap di RS Adi Husada Undaan Wetan Surabaya. Data dikumpulkan dari rekam medik semua pasien asma rawat inap yang memenuhi kriteri inklusi. Teknik analis data yang digunakan dalam penelitian ini adalah:

1. Data informasi pengobatan pasien dan data selama monitoring yang telah dikumpulkan kemudian dianalis mengenai drug-related problems (DRPs) menggunakan pustaka.

2. Melakukan analisa drug-related problems (DRPs) pada informasi mengenai pasien berdasarkan pustaka. ${ }^{1,19-21}$

3. Menganalisa normalitas persebaran data jumlah obat dan jumlah masingmasing DRPs yang dialami tiap pasien.

4. Melakukan analisa hubungan antara jumlah obat yang digunakan dengan kejadian DRPs dengan menggunakan uji korelasi. Apabila persebaran data normal (parametrik) akan digunakan uji Pearson, sedangkan apabila persebaran data tidak normal (nonparametrik) maka digunakan uji Spearman.

\section{HASIL DAN PEMBAHASAN}

Penelitian untuk mendapatkan data pasien asma rawat inap (asma akut) menggunakan metode retrospektif, dengan menganalisis data rekam medik pasien asma yang menjalani rawat inap di Rumah Sakit Adi Husada Undaan Wetan pada bulan November 2008- November 2010. Besar pasien yang memenehu kriteria inklusi dan eksklusi adalah sebesar 60 orang. Jumlah sampel dalam penelitian ini adalah 60 orang, yang 
terdiri dari 22 orang pasien laki-laki $(36,67 \%)$ dan 38 orang adalah pasien perempuan (63,33\%). Usia sampel penelitian yang paling muda adalah 20 tahun, sedangkan usia yang paling tua adalah 82 tahun. Jumlah sampel penelitian yang mengalami polifarmasi (terapi $\geq 5)$ sebanyak 49 orang $(81,67 \%)$ dari 60 orang (Tabel 1).
Jumlah kejadian DRPs yang terjadi pada sampel penelitian adalah sebesar 344 kasus, yang terdiri dari jenis DRPs obat yang diperlukan 37 kasus (11\%), obat yang kurang sesuai 226 kasus $(66 \%)$, dosis tidak tepat 10 kasus (3\%), adverse-drug reactions (ADRs) (31\%), serta interaksi obat 40 kasus (11\%) (Gambar 1).

Tabel 1. Demografik dan Karakteristik Sampel Penelitian

\begin{tabular}{|c|c|}
\hline Variabel & Total $(n=60)$ \\
\hline \multicolumn{2}{|l|}{ Jenis kelamin } \\
\hline - Laki-laki & 22 \\
\hline - Perempuan & 38 \\
\hline \multicolumn{2}{|l|}{ Age (year) } \\
\hline$-\quad 20-25$ & 6 \\
\hline$-\quad 26-30$ & 8 \\
\hline$-\quad 31-35$ & 2 \\
\hline$-\quad 36-40$ & 6 \\
\hline$-\quad 41-45$ & 5 \\
\hline$-\quad 46-50$ & 5 \\
\hline$-\quad 51-55$ & 9 \\
\hline$-\quad 56-60$ & 6 \\
\hline$-\quad 61-65$ & 4 \\
\hline$->65$ & 9 \\
\hline \multicolumn{2}{|l|}{ Lama pasien menderita asma (tahun) } \\
\hline$-\quad<1$ & 3 \\
\hline$-\quad 1-10$ & 9 \\
\hline$-\quad 11-20$ & 10 \\
\hline$-\quad 21-30$ & 1 \\
\hline$-\quad 31-40$ & 1 \\
\hline$-\quad 40-50$ & 1 \\
\hline$-\quad>50$ & 1 \\
\hline - $\quad$ Tidak diketahui & 34 \\
\hline \multicolumn{2}{|l|}{$\begin{array}{l}\text { Kondisi sampel penelitian asma akut saat keluar } \\
\text { rumah sakit }\end{array}$} \\
\hline - Membaik (sembuh) & 2 \\
\hline - Pulang paksa & 0 \\
\hline - Meninggal & \\
\hline $\begin{array}{l}\text { Jumlah rata-rata obat yang digunakan sampel } \\
\text { penelitian }\end{array}$ & 11 \\
\hline$-<5$ & 39 \\
\hline$-\quad 5-10$ & 10 \\
\hline$-\quad 11-15$ & \\
\hline
\end{tabular}




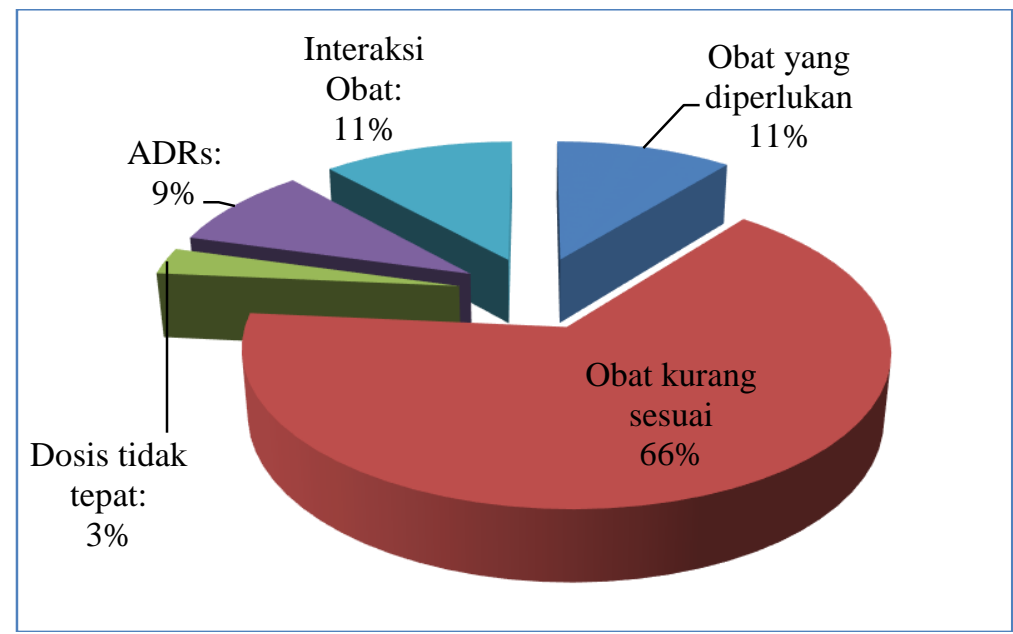

Gambar 1. Jumlah Kejadian DRPs pada Sampel Penelitian

Tabel 2. Uji Normalitas dengan Menggunakan Kolmogorov-Smirnov

\begin{tabular}{lcc}
\hline \multicolumn{1}{c}{ Data yang diuji Normalitas } & Nilai $\mathbf{P}$ & Normalitas \\
\hline Data jumlah obat yang digunakan pasien & 0.003 & Tidak normal \\
Data DRP, jenis: Obat yang diperlukan & 0.000 & Tidak normal \\
Data DRP, jenis: Obat yang kurang sesuai & 0.000 & Tidak normal \\
Data DRP, jenis: dosis tidak tepat & 0.000 & Tidak normal \\
Data DRP, jenis: adverse-drug reactions & 0.000 & Tidak normal \\
Data DRP, jenis: Interaksi obat & 0.000 & Tidak normal \\
Total DRP & 0.006 & Tidak normal \\
\hline
\end{tabular}

Data jumlah rata-rata obat yang digunakan selama di rumah sakit dan data dari macam-macam drugrelated problems (DRPs) dari masingmasinng sampel penelitian, diuji normalitas persebaran datanya dengan tes Kolmogorov-Smirnov, dan menunjukkan bahwa semua data tidak terdistribusi secara normal ( $\mathrm{P}<0.05)$ (Table 2). Obat yang diperlukan/drug needed (juga termasuk sebagai "no drug") terdiri dari obat diindikasikan tetapi tidak diresepkan; suatu masalah medis telah didiagnosa, tapi tidak ada indikasi bahwa terapi diberikan (kemungkinan terapi tidak diperlukan) dan obat diresepkan dengan benar tapi pasien tidak menggunakan (nonadherence). Obat yang salah/tidak tepat (wrong/inappropriate drug) terdiri dari tidak ada kondisi penyakit/medis yang sesuai dengan pengunaan obat, obat yang diberikan tidak memiliki indikasi yang sesuai dengan masalah medis pasien, masalah medis pasien sudah tidak ada, duplikasi dari terapi lain, adanya alternatif obat lain yang lebih murah, gagalnya pengobatan karena kehamilan, usia pasien, kontraindikasi lain, penggunaan obat-obat OTC (over-thecounter) oleh pasien yang tidak tepat, penyalahgunaan fungsi obat (recreational drug use). Dosis yang salah (wrong dose) terdiri dari dosis obat terlalu rendah/underdose (termasuk pengaturan dosis untuk fungsi ginjal, fungsi hati, usia, ukuran tubuh), dosis obat terlalu tinggi (overdose) (termasuk pengaturan 
dosis untuk fungsi ginjal, fungsi hati, usia, ukuran tubuh), durasi pemakaian obat terlalu pendek, durasi pemakaian obat terlalu panjang, peresepan dosis yang sudah tepat, tetapi pasien menggunakan obat secara overuse (overadherence), peresepan dosis yang sudah tepat, tetapi pasien menggunakan obat secara underuse (underadherence), dan interval dosis tidak benar atau kurang dari optimal (pertimbangan pengunaan sustained-release dosage forms). Yang termasuk ADRs antara lain: reaksi hipersensitivitas, reaksi idiosinkrasi, penyakit yang diinduksi oleh obat, dan perubahan laboratorium yang diinduksi oleh obat. Penilaian ADRs adalah dengan mengamati gejala klinis (toksisitas dan efek samping obat) dan hasil tes laboratorium. Interaksi obat terdiri dari: interaksi antara obat dengan obat, interaksi antara obat dengan makanan, dan interaksi antara obat yang menyebabkan perubahan hasil tes laboratorium. ${ }^{12,13,15}$
Dalam mengetahui hubungan antara polifarmasi yang terjadi pada pengobatan pasien dengan kejadian drugrelated problems (DRPs) yang terjadi pada sampel penelitian, yang terbagi dalam 5 kelompok yaitu obat tidak diperlukan, obat kurang sesuai, dosis tidak tepat, adverse-drug reaction, dan interaksi obat; maka digunakan uji Spearman untuk non-parametric test (signifikansi 0,05), yang bertujuan untuk mengetahui apakan polifarmasi mempengaruhi jenis-jenis kejadian DRPs pada pasien asma rawat inap. Hasil menunjukkan bahwa hubungan antara jumlah obat dengan jenis DRPs obat kurang sesuai memiliki korelasi yangg signifikan $(\mathrm{p}<0.05)$, sedangkan pada jenis DRPs obat diperlukan, dosis tidak tepat, adverse-drug reactions, serta interaksi obat tidak menunjukkan nilai korelasi yang signifikan $(\mathrm{p}>0.05)$ dengan jumlah obat. Total DRPs menunjukkan nilai korelasi yang tidak signifikan $(p>0.05)$ terhadap jumlah obat yang digunakan sampel penelitian (Tabel 3).

Tabel 3. Korelasi Jumlah Obat dengan Jenis-jenis Drug-Related Problems

\begin{tabular}{|c|c|c|c|c|}
\hline & & & Jumlah Obat & Hubungan Korelasi \\
\hline \multirow{15}{*}{$\begin{array}{l}\text { Jenis } \\
\text { DRPs }\end{array}$} & Obat & Pearson Correlation & .001 & \multirow{3}{*}{$\begin{array}{l}\text { Korelasi tidak } \\
\text { signifikan }\end{array}$} \\
\hline & Diperlukan & Sig. (2-tailed $)$ & .996 & \\
\hline & & $\mathrm{N}$ & 60 & \\
\hline & Obat Kurang & Pearson Correlation & $.273^{*}$ & \multirow{3}{*}{ Korelasi signifikan } \\
\hline & Sesuai & Sig. (2-tailed) & .035 & \\
\hline & & $\mathrm{N}$ & 60 & \\
\hline & Dosis Tidak & Pearson Correlation & .026 & \multirow{3}{*}{$\begin{array}{l}\text { Korelasi tidak } \\
\text { signifikan }\end{array}$} \\
\hline & Tepat & Sig. (2-tailed) & .845 & \\
\hline & & $\mathrm{N}$ & 60 & \\
\hline & Adverse Drug & Pearson Correlation & -.049 & \multirow{3}{*}{$\begin{array}{l}\text { Korelasi tidak } \\
\text { signifikan }\end{array}$} \\
\hline & Reactions & Sig. (2-tailed $)$ & .711 & \\
\hline & & $\mathrm{N}$ & 60 & \\
\hline & Interaksi & Pearson Correlation & .116 & \multirow{3}{*}{$\begin{array}{l}\text { Korelasi tidak } \\
\text { signifikan }\end{array}$} \\
\hline & Obat & Sig. (2-tailed) & .379 & \\
\hline & & $\mathrm{N}$ & 60 & \\
\hline \multirow{3}{*}{\multicolumn{2}{|c|}{ Total DRPs }} & Pearson Correlation & .192 & \multirow{3}{*}{$\begin{array}{l}\text { Korelasi tidak } \\
\text { signifikan }\end{array}$} \\
\hline & & Sig. (2-tailed) & .142 & \\
\hline & & $\mathrm{N}$ & 60 & \\
\hline
\end{tabular}

*. Korelasi signifikan pada tingkat 0.05 (2-tailed). 
Obat-obat yang digunakan pasien asma bertujuan untuk mengatasi kondisi eksaserbasi ataupun mengontrol gejala asma, namun makin banyak obat yg digunakan juga dapat meningkatkan drug-related problems (DRP). Bahkan berdasarkan penelitian ini, terjadinya polifarmasi pada pasien asma justru meningkatkan kejadian DRP jenis obat yang diperlukan, yang berarti makin banyak obat yang digunakan pasien maka makin berisiko seseorang pasien asma tidak mendapatkan obat yang sebenarnya diperlukan olehnya. Oleh karena itu dibutuhkan peran farmasis dalam memonitor dan merekomendasikan obat yang rasional bagi pasien asma yang menjalani rawat inap di rumah sakit, agar terapi yang didapatkan oleh pasien efektif dan optimal.

\section{SIMPULAN}

Terdapat korelasi antara jumlah obat dengan jenis DRPs obat yang kurang sesuai, sehingga makin banyak jenis obat yang digunakan oleh pasien asma maka makin besar risiko pasien mendapatkan obat yang kurang sesuai.

\section{DAFTAR PUSTAKA}

1. Global Initiative for Asthma. Global Strategy for Asthma Management \& Prevention (Update) 2015.

2. Asthma Management Handbook. National Asthma Counil Australia. 2006.

3. Mangunrejo H, Widjaja A, Kusumo D, Sutoyo, Yunus F, Pradjnaporamita, et al. Pedoman Diagnosis dan Penatalaksanaan di Indonesia: Asma, Perhimpunan Dokter Paru Indonesia. 2004.

4. DiPiro J, Talbert R, Yee G, Matzke G, Wells B, Posey M, editors. Pharmacotherapy:

Pathophysiologic Approach. 6th ed. United States: McGrawHill; 2005.

5. Abdelhamid E, Awad A, Gismallah A. Evaluation of a Hospital Pharmacy-Based Pharmaceutical
Care Services for Asthma Patients. Pharmacy Practice 2008; 6(1):25-32.

6. McDonald VM, Simpson JL, Higgins I, Gibson PD. Multidimensional assessment of older people with asthma and COPD: clinical management and health status. Age and Ageing 2011;40(1):42-49.

7. Veehof LJ, Stewart RE, Meyboomde Jong B, Haaijer-Ruskamp FM. The development of polypharmacy: A longitudinal study.Family Practice 2000; 17(3):261-267.

8. Koh Y, Kutty FBM, Li SC. Drugrelated problems in hospitalized patients on polypharmacy: the influence of age and gender. Therapeutics and Clinical Risk Management 2005; 1(1): 39-48.

9. Veehof LJ, Stewart RE, Meyboomde Jong B, Haaijer-Ruskamp FM. Adverse drug reactions and polypharmacy in the elderly in general practice. Eur $\mathrm{J}$ Clin Pharmacol 1999;55(7):533-6.

10. Bootman L. Drug Related Morbidity and Mortality Impact of Pharmaceutical Care, World Health Organization: Essensial Medicines and Policy Department (EDM): International Conferences on Improving Use of Medicines (ICIUM) 2007.

11. Kirsten K Viktil, Hege S Blix, Tron A Moger, Aasmund Reikvam. Polypharmacy as commonly defined is an indicator of limited value in the assessment of drug-related problems. Br J Clin Pharmacol 2007; 63(2): 187-195.

12. Cipolle R, Strand L, Morney P. Pharmaceutical Care Practice. United States: McGrawHill; 1998.p76-80.

13. Mill FV. Drug-related Problems: A Cornerstone for Pharmaceutical Care. Journal of the Malta College of Pharmacy Practice. 2005; 10.

14. American Society of Health-System Pharmacists. ASHP Guidelines on a 
Standardized Method for Pharmaceutical Care. Am J HealthSyst Pharm 1996; 53:1713-6.

15. Corelli RL, Kradjan WA, KodaKimble MA, Young LY, Guglielmo BJ, Alldredge B. Assessment of Therapy and Pharmaceutical Care. Dalam Koda-Kimble MA, Young LY, Kradjan WA, Guglielmo BJ, Corelli RL, eds. Applied Therapeutics: The Clinical Use of Drugs, $8^{\text {th }}$ ed. Philadelphia: Lippincortt Williams \& Wilkins;2005. p1.1-1.21.

16. Rovers JP, Currie JD, Hagel HP, McDonough RP, Sobotka JL, ed. A Practical Guide to Pharmaceutical Care $2^{\text {nd }}$ ed.Washington DC: American Pharmaceutical Association;2003. p160-162.

17. Blix H, Vitkil K, Asmund R, Tron M, Bodil H, Piia P, et.al. The Majority of Hospitalised Patients Have Drug-Related Problems: Result from A Prospective Study in General
Hospitals, European Journal of Clinical Pharmacology 2004; 60(9).

18. Viktil K, Blix H, Moger T, Reikvam A. Polypharmacy as Commonly Defined is an Indicator of Limited Value in the Assessment of DrugRelated Problems. British Journal of Clinical Pharmacology, British Journal of Clinical Pharmacology 2006; 63(2):187-195.

19. British Medical Association. British National Formulary 53. Royal Pharmaceutical Society of Great Britain; 2007.

20. Lacy C, Armstrong L, Goldman M, Lance L. Drug Information Handbook: A Comprehensive Resource for all Clinicians and Healthcare Professionals, $14^{\text {th }}$ ed,. United States: Lexi-Comp Inc; 2006.

21. Baxter K, ed. Stockley's Drug Interactions, $7^{\text {th }}$ ed. London: Pharmaceutical Press; 2006. p 1-11, 697. 